\title{
Ideologia meritocrática e reflexão acadêmica: a contribuição da Revista Perspectiva do ced/ufsc $(1983-2005)^{*}$
}

\author{
Elizete Ruschel** \\ Ione Ribeiro Valle***
}

\section{Resumo}

Neste estudo analisamos os artigos publicados pela Revista Perspectiva do Centro de Ciências da Educação/Universidade Federal de Santa Catarina - Brasil (1983 a 2005). Nosso interesse se voltou à ideologia meritocrática, tendo por base o conjunto de termos relacionados a essa concepção. Para tanto, repertoriamos todas as Revistas desde sua aparição em 1983 até o ano de 2005, abrangendo 47 revistas e 425 artigos. Primeiramente, analisamos os títulos e resumos dos artigos, o que nos possibilitou uma primeira seleção. Em seguida, procedemos a uma leitura mais sistemática dos artigos selecionados (num total de 14), o que permitiu construir alguns grupos temáticos. Estes foram objetos de um estudo mais minucioso, que tornou possível estabelecer algumas relaçôes e correlações entre democratização do ensino e meritocracia, seleção meritocrática numa escola democrática e formação de professores num sistema de ensino meritocrático.

Palavras-chave: Democratização da educação. Professores-Formação. Periódicos científicos.

* Uma primeira reflexão sobre este tema foi apresentada no IV Colóquio Luso-Brasileiro sobre questóes curriculares, que ocorreu em Florianópolis entre 2 e 4 de setembro de 2008, com o título "Ideologia meritocrática e currículo: Análise da Revista Perspectiva/CED/UFSC (1983-2005)”. Este estudo é resultado de um projeto de pesquisa desenvolvido no quadro do Programa Institucional de Bolsas de Iniciação Científica - PIBIC/CNPq - BIP/UFSC.

** Graduada no curso de pedagogia pela Universidade Federal de Santa Catarina.

*** Professora Adjunta do Departamento de Estudos Especializados da Educação, do Centro de Ciências da Educação na Universidade Federal de Santa Catarina. 


\section{Ideologia meritocrática e reflexão acadêmica: A contribuição da revista perspectiva (1983-2005)}

Evidentemente seria pretensioso tentar abranger o conjunto de perspectivas de pesquisa sobre os sistemas de ensino, suas políticas educacionais, a escola, seus atores e suas práticas pedagógicas, abordadas por uma revista científica, ao longo de mais de duas décadas. O desenvolvimento de estudos teóricos e empíricos e a especialização cada vez maior das áreas de investigação no interior do campo educacional, assim como o número crescente de meios de divulgação dessa produção acadêmica, tornam essa tarefa muito complexa, em razão das ambiguidades que envolvem a educação. Não se pode esquecer também das polêmicas teóricas e dos espaços de confronto que dividem os pesquisadores entre sua ação e seu engajamento, entre o universo da pesquisa e o da decisão, dificultando sobremaneira o debate intelectual entre as diferentes "comunidades" científicas que trabalham com e sobre a educação escolar.

Assim, ao nos propormos a analisar o lugar que a ideologia meritocrática ocupa na reflexão acadêmica apresentada pela Revista Perspectiva ${ }^{1}$ do centro de Ciências da Educação da Universidade Federal de Santa Catarina no período compreendido entre 1983 e 2005, inspiramo-nos em abordagens elaboradas no quadro da sociologia da educação. A pertinência dessa escolha pode ser discutida, assim como as relaçóes e correlaçóes que estabelecemos para compor o quadro de análise proposto. Ela se justifica, aos nossos olhos, porque permite articular três dimensões possíveis: a dinâmica de continuidade/descontinuidade das questóes que fundaram os estudos, a sintonia dos pesquisadores com as mudanças nas políticas educacionais e no funcionamento dos sistemas de ensino, e seu compromisso com a formação política e pedagógica dos futuros profissionais da educação.

Partindo do pressuposto que a dinâmica do processo é mais intensa que os conteúdos abordados nos diversos números e que a produção de conhecimentos sobre a educação influencia a política educacional e a composição das estruturas escolares, de modo geral, e a organização social e pedagógica da escola, de modo particular, analisamos a maneira como os ideais meritocráticos são apropriados e mencionados nos artigos publicados pela Revista Perspectiva. Trata-se de um periódico científico que divulga e socializa a "produção de conhecimentos críticos/científicos da área 
educacional", estando aberta à contribuição de professores e pesquisadores de diferentes perspectivas teóricas e pedagógicas. Esta Revista teve sua aparição em 1983, com a publicação de seu primeiro exemplar, que previa uma periodicidade semestral. Esporadicamente, com a edição de números especiais, foram lançados dois e até três números por ano, tendo a revista mantido sua semestralidade até os dias de hoje.

É consenso entre os sociólogos da educação o fato de que os ideais meritocráticos têm fundado os sistemas de ensino das modernas sociedades democráticas, seja na sua concepção, seja nas suas práticas cotidianas. No caso brasileiro, estudos recentes têm mostrado que esses ideais têm uma presença marcante na legislação educacional ${ }^{2}$, sobretudo após os anos 1930, tendo legitimado as diversas formas de seleção e de classificação executadas pela escola, com consequências profundas sobre o êxito ou o fracasso escolar. Diante dessas constataçóes, procuramos demonstrar, através da Revista Perspectiva, que as publicações científicas criam passarelas entre a pesquisa e a ação política e pedagógica, ainda que atinjam uma pequena parcela dos envolvidos nas instituiçóes de ensino. Mesmo que os métodos e as teorias nunca estejam à altura da necessária utopia (KAUFMANN, 2004), consideramos que a riqueza e diversidade das reflexóes e dos trabalhos produzidos e publicados articulam as interrogaçóes sociológicas às preocupações dominantes em matéria de escolarização.

É nesse quadro de análise, já bastante explorado pela sociologia da educação, que inscrevemos este trabalho. Nosso principal objetivo é contribuir para a ampliação do domínio de influência dos estudos científicos sobre a educação escolar, num contexto em que a produção teórica tende a ser reconhecida somente quando toma a forma de uma técnica de expertise. Por falta de um grande projeto de mobilização, o Estado tem procurado dotar-se de uma legitimidade científica, buscando o apoio de pesquisadores - de experts -, considerados como "mediadores" suscetíveis de viabilizar, junto aos profissionais envolvidos, as reformas preconizadas. Estes são escolhidos em função de sua competência científica na área, mas também de sua capacidade para produzir um saber prático e político graças às suas ligaçóes com instituiçóes produtoras de reflexóes, ao seu conhecimento do meio profissional, mas, sobretudo, em função de sua proximidade com as orientaçóes políticas dos promotores das reformas. 


\section{Da produção à difusão dos saberes sobre a escola}

O período eleito para este estudo é caracterizado por uma importante expansão das oportunidades educacionais em todos os níveis, por um aumento significativo do número de pesquisadores universitários e por um desenvolvimento considerável da formação docente. Este contexto leva os pesquisadores a deslocarem seus centros de interesse, aproximando-os das preocupaçóes do conjunto de envolvidos diretamente com a educação escolar. As consequências das diferentes dimensóes do movimento de escolarização se fazem sentir no aumento do número de publicaçóes individuais e coletivas sobre a escola e sobre suas práticas pedagógicas, produzidas não somente por especialistas em ciências humanas e sociais, mas também por profissionais da educação. Assim, para compreender as relaçóes que se estabelecem entre o ideário meritocrático e as açóes desenvolvidas no período, procuramos nos inscrever no "espírito" desse contexto, marcado por demandas de uma maior eficiência e de uma maior transparência das instituiçóes educacionais. Reconhecemos, juntamente com Van Zanten (2000, p. 12), que "toda visão de conjunto de um campo de pesquisa fica incompleta se não se levar em conta a influência das publicações."

Evidentemente, ao definir critérios de escolha e de seleção de alguns artigos - sempre em detrimento de outros náo menos importantes -, consideramos que as múltiplas abordagens contempladas nessas publicaçóes são ambivalentes. Elas fazem parte de um longo e muitas vezes solitário percurso intelectual, inscrevendo-se, portanto, numa determinada corrente de ideias e numa história profissional singular. Esses pontos de vista tanto podem designar períodos históricos e fatos mais ou menos objetivos e objetiváveis, quanto representaçóes e maneiras de conceber a diversidade de experiências vividas e sentidas no campo educacional.

Para enfrentar essas dificuldades, nos propusemos a partir de um princípio geral - a ideologia meritocrática - e analisar sob este ângulo teórico os artigos publicados na Revista Perspectiva. Para tanto, repertoriamos todos os números das revistas Perspectiva, desde o seu lançamento em 1983 até o ano de 2005. Nelas procuramos selecionar, a partir dos títulos e resumos, os artigos que remetem - direta ou indiretamente - aos ideais meritocráticos. Essa seleção foi realizada através de um levantamento preliminar, que abrangeu os termos relacionados à palavra mérito (aproveitamento, 
aptidão, capacidade, diploma, eficiência, habilitação, merecimento, moral, oportunidade, prova, seleção, título, valor, vocação) em diferentes dicionários, especialmente de língua portuguesa, francesa e espanhola. Em seguida, procedemos a uma primeira análise dos artigos selecionados, o que exigiu uma leitura mais criteriosa dos respectivos títulos e resumos. Esses dois procedimentos permitiram elaborar um catálogo minucioso e produzir algumas sínteses e notas de observação. Por último, construímos algumas categorias de análise, a fim de possibilitar a sistematização e distribuição dos artigos por grupos temáticos.

Para colocar em prática esses procedimentos, recolhemos 46 das 47 revistas publicadas no período (o número 16, lançado em 1991, não foi encontrado), abrangendo 425 artigos. A partir da leitura dos resumos desses artigos, selecionamos 14 por mencionarem - de diferentes formas - os ideais meritocráticos. Esse trabalho de "garimpagem" foi repetido duas vezes, pois, numa primeira leitura, pareceu-nos que o número de artigos era muito baixo (pouco mais de 3\%). No entanto, ao nos remetermos ao contexto histórico, percebemos que esse movimento de produção acadêmica foi fortemente influenciado pelas transformaçóes políticas e sociais. Os estudos científicos se desenvolveram num cenário de mudanças profundas em relação às expectativas e às demandas de escolarização e de prolongamento dos níveis escolares. Não se pode negligenciar, portanto, a importância que a educação escolar ocupou nas lutas por democratizaçáo da sociedade e o lugar que continua ocupando em termos de inserção profissional e mobilidade social.

A análise desses artigos permitiu compor nove grupos temáticos, construídos com base nos títulos e resumos. Observamos que alguns números focam com mais evidência um tema, enquanto outros abrangem diversos temas. Isso nos levou a compor o que denominamos de grupos temáticos isolados e grupos temáticos associados. Nos primeiros agrupamos os temas: Avaliação; Democratização do Ensino; Seleção Meritocrática; Seleção; Punição. Nos segundos reunimos os temas: Avaliação/Democratização; Democratização/Mérito; Democratização/Seleção Meritocrática; Seleção/ Punição. Esta composição temática, representada na tabela 1, mostra o ano de publicação da Revista, o número, a quantidade de artigos repertoriados em cada uma delas, a quantidade de artigos selecionados e a distribuição dos artigos segundo os grupos temáticos. 
Tabela 1 - Revista Perspectiva - 1983-2005 - Artigos Repertoriados e Artigos Selecionados/Grupos Temáticos

\begin{tabular}{|c|c|c|c|c|}
\hline \multicolumn{4}{|c|}{ Revista Perspectiva } & \multirow{2}{*}{$\begin{array}{c}\text { Grupos Temáticos } \\
\text { Temática }\end{array}$} \\
\hline Ano & $\mathrm{N}^{\mathbf{o}}$ & A.R. & A.S. & \\
\hline 1983 & 1 & 9 & 1 & $\begin{array}{c}\text { Avaliação } \\
\text { Democrátion }\end{array}$ \\
\hline \multirow{2}{*}{1984} & 2 & 9 & 1 & Selecão \\
\hline & 3 & 9 & - & - \\
\hline \multirow{2}{*}{1985} & 4 & 13 & - & - \\
\hline & 5 & 9 & 1 & Seleção \\
\hline \multirow{2}{*}{1986} & 6 & 7 & 1 & Seleção \\
\hline & 7 & 7 & 1 & Democratização/Seleção Meritocrática \\
\hline \multirow{2}{*}{1987} & 8 & 12 & - & - \\
\hline & 9 & 11 & - & - \\
\hline \multirow{2}{*}{1988} & 10 & 8 & 1 & Seleção/Punição \\
\hline & 11 & 11 & - & - \\
\hline \multirow{2}{*}{1989} & 12 & 6 & - & - \\
\hline & 13 & 6 & - & - \\
\hline \multirow[t]{2}{*}{1990} & 14 & 6 & $\begin{array}{l}1 \\
1\end{array}$ & $\begin{array}{c}\text { Seleção Meritocrática } \\
\text { Democratização do Ensino }\end{array}$ \\
\hline & 15 & 5 & 1 & Punição \\
\hline 1991 & 16 & - & - & Não encontrada \\
\hline \multirow{3}{*}{1992} & 17 & 11 & - & - \\
\hline & 18 & 8 & - & - \\
\hline & 19 & 8 & - & - \\
\hline 1993 & 20 & 5 & 1 & Democratização/Mérito \\
\hline \multirow{2}{*}{1994} & 21 & 7 & - & - \\
\hline & 22 & 7 & - & - \\
\hline \multirow{2}{*}{1995} & 23 & 6 & 1 & Avaliação/Democratização \\
\hline & 24 & 11 & - & - \\
\hline \multirow{2}{*}{1996} & 25 & 10 & - & - \\
\hline & 26 & 9 & - & - \\
\hline \multirow{2}{*}{1997} & 27 & 12 & - & - \\
\hline & 28 & 7 & - & - \\
\hline \multirow{2}{*}{1998} & 29 & 10 & - & - \\
\hline & 30 & 06 & - & - \\
\hline \multirow{4}{*}{1999} & Especial & 8 & - & - \\
\hline & Especial & 8 & - & - \\
\hline & 31 & 10 & - & - \\
\hline & 32 & 12 & - & - \\
\hline
\end{tabular}




\begin{tabular}{c|c|c|c|c}
\multicolumn{2}{c}{ Continuação } \\
\hline \multirow{2}{*}{2000} & 33 & 9 & 2 & Democratização/Seleção Meritocrática \\
\cline { 2 - 5 } & 34 & 10 & - & - \\
\hline \multirow{2}{*}{2001} & 1 & 10 & - & - \\
\cline { 2 - 5 } & 2 & 10 & - & - \\
\hline \multirow{3}{*}{2002} & 1 & 11 & - & - \\
\cline { 2 - 5 } & 2 & 11 & - & - \\
\cline { 2 - 5 } & Especial & 11 & - & - \\
\hline \multirow{2}{*}{2003} & 1 & 11 & - & - \\
\cline { 2 - 5 } & 2 & 9 & - & - \\
\hline \multirow{2}{*}{2004} & 1 & 12 & - & - \\
\cline { 2 - 5 } & 2 & 11 & - & - \\
\cline { 2 - 5 } & Especial & 8 & - & - \\
\hline \multirow{2}{*}{2005} & 1 & 08 & - & - \\
\cline { 2 - 5 } & 2 & 11 & - & \\
\hline \multirow{2}{*}{ Total } & 47 & 425 & 14 & \\
\hline
\end{tabular}

Legenda: A.R.: Artigos Repertoriados; A.S.: Artigos Selecionados.

Fonte: Revistas do Centro de Ciências da Educação/Universidade Federal de Santa Catarina (1983 a 2005).

Como pudemos observar, a grande concentração de artigos relacionados aos ideais meritocráticos está entre 1983 e 1995 (12 artigos). Trata-se de um período de desenvolvimento de um leque diversificado de trabalhos, ancorados em diferentes correntes de pensamento e diversas abordagens metodológicas, mas que, em termos gerais, caracterizam-se pelo desejo de compreender criticamente os fundamentos das políticas educacionais e o funcionamento das instituições de ensino. A maioria destes estudos se inscreve nos debates da democratização da educação, tendo como perspectiva a elaboraçáo de uma nova lei para a educação nacional. O interesse pelo tema Seleção emerge num quadro de fortes e contundentes críticas ao sistema de avaliação em vigência em Santa Catarina desde o início dos anos 1980, o chamado avanço progressivo ou, mais propriamente, a promoção automática. A temática Democratização/Seleção Meritocrática volta a ser objeto de pesquisa em 2000, com a publicação de dois artigos que vão discutir alguns aspectos das novas reformas educacionais, notadamente a questão da formação profissional, da profissionalização do magistério e da formação continuada.

A dificuldade de apreender o conjunto de elementos essenciais à compreensão das relaçóes entre os ideais meritocráticos e os temas agrupados 
nos grupos temáticos, levou-nos a compor outros quadros de referência, visando a facilitar a análise dos artigos. Assim, a tabela 2 apresenta o total de artigos selecionados (14) distribuídos entre os diferentes grupos temáticos. Nota-se que o tema Democratização/Seleção Meritocrática foi o mais recorrente ( 4 artigos), seguido pelo tema Seleção com 3 artigos. Os demais temas foram objeto de estudo de apenas um artigo cada um.

$\mathrm{O}$ fato de reunirmos diferentes autores num mesmo grupo temático não supóe abordagens fundadas em perspectivas teórico-metodológicas idênticas. Os artigos se aproximam unicamente por fazerem referência ao mesmo tema, embora com focos de interesse diversos. A maioria desses estudos foi motivada por questóes educacionais que ganham evidência nos intensos debates dos anos 1980, apresentando um caráter de denúncia, de apelo ao engajamento nas lutas pela democratização da educação, mas também de crítica aos limites e, muitas vezes, contradiçóes, das políticas educacionais em vigor; todos inscritos no quadro do regime autoritário.

Tabela 2 - Revista Perspectiva - 1983-2005 - Grupos Temáticos / Número de Artigos

\begin{tabular}{c|c}
\hline Grupos Temáticos & Número de Artigos \\
\hline Avaliação & $\mathbf{1}$ \\
\hline Avaliação/Democratização & $\mathbf{1}$ \\
\hline Democratização do Ensino & $\mathbf{1}$ \\
\hline Democratização/Mérito & $\mathbf{1}$ \\
\hline Democratização/Seleção Meritocrática & $\mathbf{4}$ \\
\hline Seleção Meritocrática & $\mathbf{1}$ \\
\hline Seleção/Punição & $\mathbf{1}$ \\
\hline Seleção & $\mathbf{3}$ \\
\hline Punição & $\mathbf{1}$ \\
\hline Total & $\mathbf{1 4}$ \\
\hline
\end{tabular}

Fonte: Revistas do Centro de Ciências da Educação/Universidade Federal de Santa Catarina (1983 a 2005).

O estudo dos artigos selecionados permitiu estabelecer novas relações e correlaçóes, tendo ficado claro, desde o início, que não seria possível esgotar a análise interpretativa, mas somente fundamentar um ponto de vista a partir de diferentes pontos de vista. Decidimos então enfocar alguns aspectos que 
nos pareciam mais interessantes e, sobretudo, que nos permitiam tecer um fio de Ariadne explicativo. Esta decisão inspirou-se em estudos sociológicos recentes, os quais vêm mostrando que o campo empírico tem uma força tão grande, que pode dificultar o voo audacioso das ideias. Segundo Kaufmann (2004, p. 5), "os conceitos permanecem colados nos fatos, estando limitados a um baixo nível de abstração, à incapacidade de articulação entre si para a formação de um verdadeiro quadro teórico."

Assim, fizemos um novo agrupamento dos artigos selecionados, considerando as características mais ou menos gerais dos conteúdos neles abordados, por percebermos que alguns deles enfocavam diferentes perspectivas, na maioria das vezes críticas, sobre a meritocracia escolar. Isso tornou possível recorrer a eles várias vezes, assim como a alguns outros estudos sociológicos, para analisar três diferentes rubricas. A primeira, democratização do ensino e meritocracia, refere-se essencialmente à política educacional brasileira, tendo por alvo seus princípios e suas promessas. Os artigos de Fiod (1983), Pereira (1986), Evangelista (1993), Hannah (2000) e Shiroma (2000) constituíram-se nas principais fontes. A segunda, seleção meritocrática numa escola democrática, dá continuidade à análise crítica das políticas educacionais, tendo por centro, sobretudo, os processos avaliativos. Sena (1983), Girardi (1984), Valença (1985, 1988), André e Leite (1986), Siqueira (1990) e Koch (1995) forneceram os fundamentos para a análise desse tema. Enfim, a última rubrica, formação de professores num sistema de ensino meritocrático, inscreve-se igualmente no quadro de críticas às políticas educacionais, tendo por interesse as reformas voltadas à formação docente. Pereira (1986), Evangelista (1990), Fiod (1990) e Shiroma (2000) abordam de maneira mais sistemática esta questão.

\section{Democratização do ensino e meritocracia}

A ideologia meritocrática fundamenta nossos sistemas educacionais ao menos desde os anos 1930, quando os pioneiros da educação nova se engajaram num movimento em favor da escolarização dos brasileiros definindo seus pressupostos, até os dias atuais, com a promulgação da Lei de Diretrizes e Bases da Educação Nacional (1996). A educação escolar aparece nos dispositivos legais como um mecanismo de equidade e de justiça social, ao considerar que são oferecidas oportunidades iguais aos 
indivíduos quando ingressam na escola. As diferenças de rendimento escolar dependem, portanto, unicamente do interesse e do esforço de cada um. Nesta perspectiva, as desigualdades sociais, amplamente reconhecidas como injustas pela filosofia política da era moderna por estarem relacionadas ao nascimento e à herança, são substituídas por "desigualdades justas" (DUBET, 2008), decorrentes exclusivamente da capacidade, da vocação, dos dons e méritos individuais. Assim, as desigualdades passam a ser justificadas pelas qualidades pessoais dos alunos, sendo que os que demonstram talento, motivação e aptidão terão êxito na carreira escolar e profissional, com consequências efetivas sobre a vida social. Dessa maneira, atribui-se ao aluno toda responsabilidade pelo seu êxito ou fracasso, desconsiderando-se que estes estão ligados à sua origem econômica e social, assim como aos processos pedagógicos realizados pelo sistema escolar, tal como comprovam, desde a década de 1960, os estudos dos chamados "reprodutivistas".

Segundo Costa (1984), existem duas distinções básicas relativas ao princípio de igualdade de oportunidades educacionais: uma identifica igualdade de oportunidades com igualdade de acesso à escola; outra relaciona igualdade de oportunidades à igualdade de sucesso ou de resultados. A primeira volta-se ao início do processo de escolarização, a segunda enfoca o fim desse processo. Fica, portanto, evidente que não é possível concretizar o princípio de igualdade de oportunidades sem se assegurar da igualdade de condições, pois o simples ingresso na escola não proporciona a igualdade de resultados.

Do ponto de vista das políticas educacionais, cuja inspiração remonta ao projeto republicano, o acesso à educaçáo escolar sempre esteve ligado à perspectiva de um futuro melhor, à expectativa de mobilidade social, tendo inspirado as lutas pela expansão das oportunidades escolares em diferentes momentos históricos. À escola é atribuída a responsabilidade pela conquista da justiça social. Ela ocupa assim um lugar central nos movimentos sociais e nas lutas revolucionárias e tem compromisso com a transformação da sociedade. Ao analisar os principais instrumentos do projeto democrático de Anísio Teixeira, Evangelista (1993, p. 93) sublinha a responsabilidade do Estado no que concerne à organização de instituiçóes voltadas às necessidades sociais. Segundo ela, seu

ideário democrático residia no fato de dar a cada um oportunidades iguais para que cada um se 
desenvolvesse pelas suas competências e capacidades individuais. Nessa democracia a localização social não se faria por mero interesse político ou de classe, ou pela passagem por uma escola cujo privilégio estava em promover a ascensão social, mas pelos méritos que cada um provasse possuir.

As consideraçóes da autora permitem afirmar que os princípios meritocráticos serviram de base às reformas educacionais, estando ligados ao ideário democrático que tem justificado as diferenças sociais e de rendimento escolar, mas também tem fundamentado os movimentos em favor da escolarização e as lutas pela expansão das oportunidades de acesso aos diferentes níveis escolares.

Numa perspectiva que relaciona as reformas educacionais à conjuntura internacional do final do milênio, Shiroma (2000) assinala que a abertura da economia brasileira resultou numa grande precarização das condiçóes de trabalho e dos salários, o que repercutiu sobre o aumento do desemprego e, consequentemente, da miséria e da exclusão social. Isso ocorreu devido ao despreparo das empresas nacionais, que se mostraram em desvantagem na competição com os mercados estrangeiros, bastante avançados em termos de desenvolvimento tecnológico. Neste contexto, a educação ganha grande visibilidade nos congressos internacionais, que provocaram um número significativo de publicaçóes e difundiram as diretrizes gerais para as políticas educacionais de um mundo globalizado. A educação, que deveria ser objeto de grandes reformas, aparece como solução para os problemas nacionais, sendo considerada "capaz de promover a empregabilidade dos cidadãos e assegurar aos mais capazes, os melhores salários.” (SHIROMA, 2000, p. 81). A reforma educacional brasileira, promovida na década de 1990, centrouse, portanto, na avaliação, no currículo, na gestão, no financiamento e na formação de professores. Para Shiroma (2000), o governo, além de incentivar a autonomia financeira das escolas e universidades, restringiu a participação popular ao auxílio financeiro e às açóes voluntárias. O governo estabeleceu, também, estratégias para reduzir os índices de evasão e repetência, como os programas de aceleração da aprendizagem e de flexibilização de retorno aos evadidos do sistema educacional, mas em momento algum promoveu a igualdade de oportunidades. 
Observa-se, a partir de Fiod (1983) e de Shiroma (2000), que a política de profissionalização, que teve um caráter obrigatório nas reformas do regime autoritário, é retomada nos projetos educacionais atuais, reeditando-se assim a dualidade de percursos que tem marcado o sistema educacional brasileiro. Para Fiod (1983), no ensino de segundo grau (atual Ensino Médio), reafirmou-se a dualidade histórica, expressa nas duas tendências: as escolas profissionalizantes para os que não apresentam condições de investir numa carreira escolar mais longa e as escolas propedêuticas para os que podem ascender na hierarquia educacional. Os sistemas de ensino desenvolvem, portanto, uma prática escolar seletiva e classificatória, que favorece determinadas classes, em detrimento das expectativas e das necessidades das demais. Segundo Shiroma, visando a reduzir os gastos públicos com o ensino superior, a política do governo Fernando Henrique Cardoso deu ênfase à educação profissional: "a reforma do ensino técnico, iniciada em 1997, funciona como um mecanismo de contenção da demanda para o superior, ao regulamentar a oferta do ensino técnico-profissionalizante desvinculado da educação básica” (SHIROMA, 2000, p. 82).

Para que os princípios meritocráticos se mantenham nos sistemas educacionais e justifiquem as práticas excludentes, o governo aplica estratégias disseminadas pelos organismos multilaterais, que incentivam a competitividade, incorporando, em grande escala, os propósitos mercantis na educação. Nesse sentido, Hannah (2000, p. 116) assinala que a educação "tornou-se mercantil mediante a introdução de mecanismos de mercado no financiamento e gerenciamento das práticas educacionais. Tornou-se uma mercadoria, um produto a ser consumido.” Para Shiroma (2000, p. 88 ), o projeto dos organismos multilaterais visa a formar uma cultura de conformação, que reconhece as desigualdades sociais como naturais, por acreditar que o êxito ou o fracasso do indivíduo decorre unicamente de sua competência: "nesse projeto, a educação é 'para todos' mas não é a mesma para todos." Assim, a educaçáo de qualidade fica restrita aos que podem custear seus estudos, e, aos demais, resta a educação profissional, inclusive com certificação independente da escolaridade anterior. $\mathrm{O}$ trabalho de Hannah (2000, p. 116) avança nesta mesma direção, ressaltando que à educação é atribuída "a função de formar a força de trabalho com as competências necessárias para atender as demandas de um mercado cada vez mais exigente e excludente." 
Como sabemos, a educação de qualidade e os longos percursos de escolarização têm se destinado historicamente aos que possuem as melhores condiçóes econômicas e sociais, pois somente quem recebe uma formação acadêmica sólida, disponibilizada quase que exclusivamente pelas escolas particulares, consegue enfrentar os tão disputados concursos vestibulares das universidades públicas. Aos egressos das escolas públicas ficam, portanto, destinados os cursos superiores pagos. Para Shiroma (2000, p. 81), as facilidades para o ingresso em determinados cursos, previstas pela LDB de 1996, resultaram numa propagação de cursos estruturados em módulos ou à distância que, "se por um lado favorecem o acesso dos trabalhadores aos estudos, por outro, se estiverem desatrelados a uma sólida formação básica que lhe dê suporte, podem transformar-se em 'perfumaria' que contribui apenas para engordar a coleção de certificados."

Analisando a desqualificação da educação no Brasil, Pereira (1986) argumenta que ela é reflexo direto da estrutura social. O baixo rendimento obtido nos vestibulares é geralmente atribuído à história escolar do aluno, resultando, sobretudo, da má formação praticada no ensino de segundo grau (obrigatoriamente profissionalizante). Este nível de ensino repassa a responsabilidade ao ensino de primeiro grau (atual Ensino Fundamental), que, por sua vez, atribui o fracasso escolar às más condições de vida dos alunos, isentando a escola de todo envolvimento no processo de escolarização. Entretanto, à escola cumpre um papel de perpetuação das desigualdades sociais próprias do modelo capitalista, ao difundir conteúdos irrelevantes a amplas esferas da sociedade, assegurando, assim, os privilégios de uma minoria. Parece evidente que a escola tende a selecionar os socialmente privilegiados - os que frequentaram instituiçóes privadas, reconhecidas como de boa qualidade -, os que ingressarão nas universidades públicas e se preparam para ocupar as funçóes políticas de prestígio e para gerir o processo produtivo. Segundo Pereira (1986, p. 1920), já está evidenciado que "o fracasso escolar é um problema que só pode ser resolvido estruturalmente, porque é um produto 'natural' da estrutura social, econômica e política vigente no Brasil.” É importante destacar, também, que "as características destes fatores estruturais, determinantes na configuração do destino histórico da sociedade brasileira” constituem um verdadeiro "exército de excluídos da educação, da saúde, etc." Sem essas constataçóes, afirma o autor, não se pode 
compreender a natureza da crise que atravessa a sociedade brasileira, onde a educação é muito mais um reflexo do que um agente causador, embora, pela sua própria função, possa ser um elemento decisivo na superação desta crise, em sua luta pela constituição de uma sociedade onde esteja assegurado o direito ao pleno exercício do ato educativo. (PEREIRA, 1986, p. 19-20).

As consideraçóes dos autores nos remetem aos ideais da ideologia meritocrática, ancorados nos diplomas que se constituem em meios de legitimar e comprovar o mérito pessoal: o diplomado é aquele que obteve êxito unicamente pelo seu próprio esforço. Os concursos, exames e provas figuram como dispositivos de seleçáo dos mais aptos para ocuparem a função pretendida. Assim, os indivíduos que obtiverem mais títulos e comprovarem mérito e talento pessoal pelos processos seletivos, serão reconhecidos como legítimos para o exercício dessas funções. Mas não podemos ignorar o que Bourdieu (2007) denomina de “inflação de diplomas", mecanismo presente nas estratégias de reprodução, o que não assegura uma distribuição igualitária das vagas de trabalho. Encontramo-nos, enfim, diante de uma estrutura educacional altamente reprodutiva, já denunciada pelos sociólogos da educação desde meados do século XX, e que coloca em prática mecanismos de legitimação das desigualdades que produz e reproduz.

\section{Seleção meritocrática numa escola democrática}

Se pensarmos nos sistemas educacionais que se proclamam democráticos, fundados no princípio de igualdade de oportunidade todos os indivíduos ao ingressarem na escola deparam-se com condiçóes educacionais idênticas -, perguntamo-nos, então, qual seria o objetivo da avaliação e se a avaliação contribui para melhorar o rendimento escolar de todos os alunos.

Ao analisar o uso do exame classificatório - principal dispositivo de avaliação -, Kreimer (2000), inspirando-se no pensamento de Foucault, considera-o como um tipo particular de exercício do poder ligado ao saber, o que sugere um olhar normalizador, "uma vigilância que permite qualificar, classificar e castigar." A autora mostra que os alunos são submetidos a exames 
a partir da noção de normal e de anormal, sendo que, nos exames escolares, eles são constantemente comparados aos seus colegas. Desse modo, o exame permite diferenciar, excluindo e punindo os não merecedores, e promover e recompensar os que comprovam mérito, e que se tornam os eleitos.

Segundo Kreimer (2000), o exame é uma ferramenta empregada pela burguesia para a consagração e a certificação do mérito, aparecendo como um "método de seleção por excelência da meritocracia." Nesta perspectiva, a avaliação tornou-se um modo de selecionar os indivíduos segundo as suas capacidades e talentos, justificando as diferenças de rendimento e de êxito escolar. O exame tem por objetivo favorecer os detentores da cultura dominante, que são também os mais familiarizados com os códigos escolares, e selecionar aqueles que já fazem parte das classes privilegiadas, mantendo-os na posição social em que se encontram: "Por seu conteúdo e por sua forma, o exame tem sido considerado o regulador fundamental para a aquisição da cultura legítima, revelando, como têm notado teóricos da reprodução (Bourdieu e Passeron, entre outros), a autonomia relativa do sistema educativo em relação ao sistema de classes.” (KREIMER, 2000). Neste sentido, o exame é usado como mecanismo de controle, pelo qual o aluno é, ao mesmo tempo, vigiado e punido, sendo que a avaliação pode se constituir em prêmio ou castigo. Assim, o aluno, quando obtém um bom resultado, ou seja, recebe uma nota alta, que comprova seu mérito, vai sentir-se recompensado pelo seu esforço; do mesmo modo, o aluno que recebe uma nota baixa, vai sentir-se culpado por não se ter esforçado o suficiente, encarando o resultado do exame como um castigo merecido. $\mathrm{O}$ exame escolar legitima, portanto, o ideal meritocrático.

Kreimer (2000) ressalta ainda que, desde o século XVIII, os castigos corporais passam a ser substituídos por castigos inferidos à alma. Os sistemas educacionais recorrem ao exame para cumprir esse papel, pois ele permite tanto castigar quanto recompensar, selecionar e excluir os alunos que não comprovarem mérito para darem continuidade à carreira escolar. Kreimer (2000) considera o exame como "uma ferramenta fundamental das sociedades disciplinarias", pois "o sistema de exames torna necessário submeter constantemente o aluno a provas para que distinga entre as verdades científicas e a mera superstição ou crença irracional, entre a informação objetiva e a interessada." 
A perspectiva apresentada acima é reafirmada nos estudos desenvolvidos por Saul (1994), para quem a avaliação escolar acaba assumindo uma função meramente seletiva, ainda que, para grande parte dos professores, ela vise a verificar apenas o rendimento escolar de seus alunos. Da forma como vem sendo executada, a avaliação não promove uma mobilização em favor de um maior envolvimento dos alunos no processo de ensino-aprendizagem, nem mesmo para os professores, já que estes não costumam retomar os conteúdos náo aprendidos.

Valença (1985) mostra que as crianças ingressam na escola em condições diferentes, não apenas em relação às suas características pessoais, mas, sobretudo, em função do meio social e cultural a que pertencem. Ao não levar essas especificidades em consideração, a escola acaba perpetuando as desigualdades e contribuindo para consolidar as injustiças sociais, seja pela seletividade dos saberes escolares, seja pelas práticas pedagógicas que realiza. Além disso, segundo Valença (1985, p. 111), a qualidade da relação entre pais e filhos afeta o desenvolvimento da inteligência e da personalidade da criança. Pautando-se nas pesquisas de Diatkine, a autora observa que, nas famílias em que a comunicação é mínima e a linguagem se reduz a fins desagradáveis (como ordens ou puniçóes), a criança passa a não sentir prazer para usar a linguagem, permanecendo na linguagem de ação. Já nas famílias que têm o hábito de usar a linguagem para fins agradáveis, "a criança desenvolve cedo a linguagem de relato e torna-se capaz de fazer abstração e elaborações igualmente cedo." (VALENÇA, 1985, p. 111). Segundo seus estudos, a linguagem de ação é a que predomina nas classes populares, sendo que, na escola, é utilizada a linguagem de relato, o que favorece as crianças a ela habituadas. Neste sentido, a escola tende a possibilitar a perpetuação das desigualdades sociais de origem e a reproduzir as injustiças sociais, mas é sobre cada um que recaem as responsabilidades sobre os veredictos escolares. Além disso, Valença (1985, p. 115) constatou que existem grandes diferenças de oportunidade escolar entre as crianças de diferentes níveis sociais, como a inexistência da pré-escola para a maioria das crianças das classes populares: "há uma defasagem de cerca de 2 anos de idade real e de desenvolvimento entre as crianças privilegiadas e desprivilegiadas por ocasião do período de alfabetização.”

As constataçóes da autora nos levam a reafirmar a importância do direito à educação - bandeira de luta dos movimentos pela democratização 
da educação - desde a mais tenra idade. Isto lhes permitiria, desde muito cedo, experimentar e vivenciar outras linguagens e situaçóes ausentes ou distantes do cotidiano familiar. No entanto, segundo Girardi (1984, p. 21), as crianças de famílias de baixo poder aquisitivo, raramente frequentam a educação infantil, quando conseguem uma vaga, recebem apenas um atendimento inadequado em instituições que não contam com profissionais especializados. A inexistência de vagas para esse nível escolar faz com que somente as famílias com maior poder aquisitivo possam proporcionar a seus filhos uma boa educação pré-escolar. Os estudos de Girardi (1984, p. 21) mostram que

as famílias de baixa renda dificilmente têm acesso a este tipo de ensino e quando isto acontece na maioria das vezes, trata-se de um trabalho de caráter assistencialista, mais voltado para a 'guarda' e alimentação das crianças por um ou dois turnos diários, do que para a orientação e estimulação das mesmas.

Nota-se, assim, que a seletividade das crianças inicia já na educação infantil, período de escolarização que permanece um privilégio das classes médias e altas em razão da insuficiência de vagas. Os filhos dessas classes frequentam instituiçóes que atendem um menor número de crianças por sala, dispóem de materiais mais adequados e de profissionais mais qualificados. Como as crianças, devido às suas vivências familiares, chegam à escola com experiências anteriores diferenciadas, as desigualdades de origem tendem a se agravar: "na seletividade do seu conteúdo programático; na transmissão seletiva; no uso abusivo dos testes de QI; dos testes de aptidão, etc." (VALENÇA, 1985, p. 117). Desse modo, pode-se perceber que a escola não proporciona igualdade de oportunidades, muito menos de condiçóes. A infância brasileira é dividida, desde o nascimento, pelo lugar onde reside, pelo acesso aos diferentes serviços sociais e culturais, pela rede de ensino que frequenta, pelos currículos escolares a que está submetida, pelos professores (mais ou menos qualificados, mais ou menos comprometidos) que encontra.

André e Leite (1986, p. 49), tendo por base uma pesquisa realizada numa escola da periferia do Rio de Janeiro, perceberam que a maioria das crianças apresenta um atraso de escolaridade. As autoras constatam que, nos momentos em que eram censuradas ou criticadas pelas professoras, essas 
crianças reagiam sem deixar de demonstrar interesse pelo aprendizado dos conteúdos: "Essas atitudes são entendidas como tentativa de resistência na medida em que as crianças não parecem introjetar o papel a elas atribuído de dominadas." A resistência dos alunos se manifesta nos comportamentos de desobediência e desrespeito ou "em atitudes como a bagunça dentro de sala quando a professora se ausenta, o resistir à realização das atividades, às respostas irônicas reivindicando comentários da professora, ao riso e à brincadeira escondidos dentro da sala.” (ANDRÉ; LEITE, 1986, p. 51). Segundo as autoras, mesmo que a escola reproduza as idéias e valores da classe dominante, os alunos tentam resistir a essa dominação, preservando e defendendo sua cultura. A desobediência aparece como uma forma de negar a massificação, pois "a escola, ao mesmo tempo em que contribui para a inculcação e a divulgação da ideologia dominante, é um espaço onde interagem sujeitos com determinada intenção" (ANDRÉ; LEITE, 1986, p. 49).

As ambiguidades da escola - que oscila entre reprodutora e democrática-, refletem-se nos argumentos dos pesquisadores. Siqueira (1990, p. 87) mostra que a escola e a sala de aula são atravessadas por relaçóes de poder. Nelas não existe, explicitamente, dominador e dominado, embora haja uma constante "guerra" entre poder e resistência: "trata-se de um jogo sutil que muda a cada momento. Muda a trama e, com ela, seu efeito de superfície, seu rosto visível. Este campo é, portanto, potencializado." Tudo depende dos agentes e dos dispositivos aos quais recorrem. A avaliação é um desses dispositivos cercados de ambiguidades. Segundo Saul (1994), a avaliação tem-se tornado um dos principais objetivos da prática pedagógica: é em torno dela que tudo gira, pois o processo de aprendizagem, de produção de conhecimentos e a relação professor-aluno baseiam-se unicamente na avaliação. Sua função está presente nas representaçóes dos diferentes agentes envolvidos na ação pedagógica. Para Saul (1994, p. 64), tudo se passa, tudo se explica, tudo se justifica em nome da avaliação: "o aluno vai ou não vai para a Escola, faz ou não faz a lição, fala ou não fala determinadas coisas, comporta-se de uma maneira ou de outra; isto porque tem a avaliação"; os professores recorrem a ela, utilizando-a durante a maior parte do tempo como "sistema de controle da disciplina, das tarefas e de tudo o que acontece"; os pais também se orientam "em função de perseguir como está a avaliação do aluno na Escola." 
Os mecanismos de avaliação também são objetos de interesse de alguns estudos publicados na Revista Perspectiva. Os pontos de vista se dividem: uns argumentam em favor da promoção automática, outros colocam em dúvida a eficiência desse sistema. Para Sena (1983), a retenção (reprovação) dos alunos não traz nenhum benefício, pois desmotiva o aluno para a atividade escolar, o que muitas vezes provoca a evasão. Além disso, o aluno repetente vai continuar ocupando uma vaga que poderia ser passada para outro aluno. Para o autor, o sistema de promoção embasado na idade cronológica do aluno é um modo mais justo, se comparado ao sistema de seriação com duração fixa. A promoção automática possibilita uma avaliação que respeita os diferentes ritmos de aprendizagem e, por consequência, leva à diminuição da evasão escolar. Koch (1995), por sua vez, questiona a eficiência do sistema de promoção automática na construção de uma escola democrática, tendo por referência a experiência da rede de ensino catarinense. Segundo ela, antecedendo-se à Lei no 5.692/1971, Santa Catarina introduz uma nova política educacional para atender às novas demandas da economia, centrada fundamentalmente no chamado avanço progressivo. Visando a possibilitar a qualificação da força de trabalho reclamada pela industrialização e com o intuito de diminuir a evasão escolar e os baixos índices de escolaridade que se tornaram escandalosos na década de 1970, extinguiu-se a reprovação escolar através do avanço progressivo e/ou promoçáo automática. Embora se tenha proposto a promover a democratização do ensino e a qualificação para o trabalho, Koch (1995) afirma que esse sistema de avaliação visava exclusivamente à diminuição dos gastos com a educação. Esse sistema, no início, pareceu positivo, pois atacou o problema já cristalizado da repetência escolar nos primeiros anos, acelerou o fluxo de saída dos alunos e favoreceu o aumento do número de vagas. Mas, muito rapidamente, isso repercutiu na qualidade do ensino, servindo para dissimular o fracasso escolar e confirmar o caráter nada democrático do sistema público de Ensino Fundamental e Médio.

Enfim, muitos estudos demonstraram que o sistema de avanço progressivo não contribuiu para a democratização da educação, sobretudo por ter sido implantado de forma autoritária pelos altos escalóes técnicoadministrativos, que tinham como objetivo unicamente ampliar o número de vagas sem expandir as redes de ensino, ao contrário, diminuindo as despesas com educação. A falta de investimentos na estrutura, a ausência de apoio 
técnico-pedagógico às escolas e a inexistência de mecanismos de recuperação no decorrer do ano letivo, nas séries iniciais, "empurrou" os alunos com dificuldades para as classes de recuperação (nas $4^{\mathrm{a}}$ e $8^{\mathrm{a}}$ séries); classes que se tornaram verdadeiros exílios para os alunos em dificuldades escolares.

Para Valença (1988, p. 46), muitas escolas teoricamente se consideram idealistas e humanistas, mas, na prática, mostram-se segregadoras e elitistas. Elas fazem uso de uma transmissão seletiva, justificada na "objetividade científica, no sentido de impedir a matrícula de crianças na escola ou em determinada classe, constituindo-se em muitas ocasióes num álibi para julgar e relegar alguns alunos e definir objetivos bem distanciados daquilo que reverteria em seu próprio bem." As escolas se tornam segregadoras pelo fato de negarem e desrespeitarem as necessidades e especificidades das crianças, as quais são vistas como vazias de cultura e, portanto, incapazes de galgar os degraus até mesmo da escolaridade obrigatória.

\section{Formação de professores para um sistema de ensino meritocrático}

Em decorrência da abertura da economia brasileira nos anos 1990, as condiçóes de trabalho e os salários se tornaram ainda mais precários, levando ao aumento do desemprego e, por conseguinte, da miséria e da exclusão social. Tendo em vista que o mercado encontrava-se cada vez mais exigente quanto à qualificação profissional, ampliou-se a procura pela educação, pois se esperava que ela favorecesse a inserção no mercado de trabalho e a ascensão social.

Segundo Shiroma (2000), a dificuldade de ingresso no mercado de trabalho resultou numa crescente procura pela educação regular e/ou profissionalizante, o que rapidamente impulsionou a expansão das redes de ensino e explicitou a falta de professores, com reflexos importantes sobre os programas de formação. Devido ao aumento da oferta e a falta de profissionais, modificou-se o conceito de educaçáo escolar a partir da LDBEN de 1996. Esta passou a poder ocorrer em diversos espaços. Além disso, essa Lei estabeleceu que, até 2006, todos os professores, indistintamente de nível de atuação, deveriam ter curso superior. No entanto, esta formação superior não significava necessariamente formação universitária. Assim, a partir do Decreto $\mathrm{n}^{\circ} 3.276 / 1999$, as universidades passariam a formar apenas os especialistas e 
licenciados, enquanto os professores para as séries iniciais e a educação infantil seriam formados nos institutos, recebendo uma formação menos qualificada em comparação com a dos demais. Trata-se, segundo a autora, de "um exemplo do princípio de equidade aplicado à educaçăo, a de se oferecer uma educação pobre aos pobres." (SHIROMA, 2000, p. 85). Para Pereira (1986), investir na formação do professor significa contradizer a lógica do capital e opor-se aos projetos de aceleramento da preparaçáo para o magistério. Nesse sentido, ao professor é atribuída a responsabilidade de enfrentar e resolver os problemas que levam ao fracasso escolar, problemas que abrangem as deficiências materiais da escola, o salário dos professores, assim como os problemas sociais que caracterizam a vida da maioria dos alunos.

Evangelista (1990, p. 35) analisa a relação entre a política e a educação, retomando a noção de educaçáo escolar desenvolvida por Carlos Roberto Jamil Cury, para quem a função da escola é difundir e elaborar concepçóes de mundo e conhecimentos. A autora reconhece, no entanto, que a escola difunde concepçôes e conhecimentos que interessam às classes dominantes, pois, ainda que inconscientemente, "os agentes pedagógicos agem no âmbito da hegemonia burguesa $\mathrm{x}$ hegemonia proletária, divulgando e consolidando principalmente a concepção de mundo própria da burguesia." (EVANGELISTA, 1990, p. 35). A autora assinala, apesar disso, que uma boa formação do professor é fundamental para que os saberes escolares sejam apresentados aos alunos de forma crítica. Isto lhe permitiria refletir sobre as diferentes concepçóes de mundo e compreender o funcionamento da sociedade, o que possibilita uma maior participação política e contribui efetivamente na luta por uma sociedade mais igualitária e justa, se retomarmos a perspectiva de Dubet (2008).

Para Evangelista (1990, p. 36), à escola pública cabe socializar o saber de forma competente e qualificada para que o aluno possa compreender sua realidade concreta. $\mathrm{O}$ acesso ao conhecimento pode promover uma nova cultura e levá-lo a "superar saberes alienantes e elaborar uma visão de mundo baseada no conhecimento científico-filosófico, coerente com sua própria inserção econômica, social e cultural." A autora reafirma a importância da conscientização dos professores sobre as intençóes ideológicas presentes nos saberes difundidos pela escola, pois ao compreenderem que o conhecimento científico nâo é neutro, poderão contribuir para a superação do senso comum e fazer com que a educaçãoo escolar se torne emancipatória. 
A perspectiva de uma formação profissional que promova o engajamento dos professores nos movimentos de transformação social dá o tom às pesquisas desenvolvidas desde os anos 1980. Fiod (1990, p. 25) sublinha que a educação só poderá se tornar um instrumento de emancipação da classe operária, quando conseguir superar a dicotomia entre teoria e prática. $\mathrm{O}$ apelo à militância docente ocupa o centro dos debates: o professor deve "enfrentar o desafio de organizar a escola e, consequentemente, o aluno trabalhador." Da escola, espera-se que se vincule "ao trabalho político que vem sendo realizado pelos setores mais organizados da classe trabalhadora. Aí a práxis escolar estará dialeticamente unindo teoria e prática - escola e trabalho - conforme interessa ao trabalhador."

Para finalizar, observamos que os autores dos artigos pesquisados, assim como as obras que serviram de referência para este trabalho, mantêm uma visão bastante crítica em relação à apropriaçáo e implantação da ideologia meritocrática nos sistemas de ensino. Esta tonalidade crítica, sem desaparecer, atenua-se nos momentos em que as pesquisas pareciam mais fortemente engajadas na ampliação das oportunidades escolares e nos movimentos de democratização da educação. Também pudemos perceber que os autores vislumbram um diálogo com seus diferentes públicos, mostrando-se muito abertos às implicações políticas e pedagógicas de seus trabalhos. Espera-se que os diversos agentes, longe de se constituírem numa audiência passiva, apropriem-se das reflexóes científicas e interroguem-se sobre sua atuação prática e política.

Nota-se, também, que existe uma grande preocupação em relação à conscientização dos professores em formação. Espera-se que deixem de perpetuar os ideais meritocráticos e que contribuam para a superação do senso comum que leva à reprodução das estratégias de dominação. Somente assim, a educação poderá alcançar o verdadeiro propósito da democratização e da justiça social. A escola poderá se constituir num dos espaços de socialização e de produção de conhecimentos capazes de instrumentalizar a todos, deixando de ser um lugar de inculcação e de transmissão de um arbitrário cultural que valoriza apenas a cultura de uma pequena minoria, promovendo sua distinção, em detrimento do interesse dos demais.

O conjunto dos estudos defende, enfim, o investimento numa formaçáo política e pedagógica de qualidade para os futuros profissionais, num esforço contínuo de enfrentamento das prerrogativas dos organismos multilaterais, traduzidas nas imposiçóes e recomendações oficiais. Para que 
tenha condições de refletir sobre os propósitos da educação, as finalidades implícitas ou explícitas dos currículos escolares, tornando-se atores de sua própria ação pedagógica, é preciso que cada um faça renascer a flama do saber, portadora de "paixão, a mais louca, a mais devorante, aquela da exploração dos mistérios do homem e do mundo", nos termos de Kaufmann (2004, p. 325). Mas é necessário também que cada um aprenda a se distanciar de seu universo especializado, que pode levar tanto à redução da razão a certos interesses, quanto à alienação, e se engaje na denúncia das injustiças sociais, em geral, e das injustiças escolares em particular.

\section{Notas}

1 Esta Revista foi apresentada como fruto do anseio e de esforços dos departamentos de Metodologia de Ensino, de Estudos Especializados em Educação e de Biblioteconomia e Documentação, e também do Colégio de Aplicação e do Núcleo de Desenvolvimento Infantil, todos integrantes do Centro de Ciências da Educação.

2 Este estudo se desenvolveu no quadro de outra pesquisa, voltada essencialmente à análise do tema meritocracia escolar. Ver: Valle e Ruschel (2009, 2010).

\section{REFERÊNCIAS}

ANDRÉ, M. E. D. A. de; LEITE, S. B. A aprendizagem da subordinação e da resistência no cotidiano escolar. Perspectiva, Florianópolis, ano 3, n. 6, p. 39-52, jan./jun.1986.

BOURDIEU, P. A distinção: crítica social do julgamento. São Paulo: Edusp; Porto Alegre: Zouk, 2007.

BOURDIEU, P.; PASSERON, J.-C. A reprodução: elementos para uma teoria do sistema de ensino. Rio de Janeiro: Francisco Alves, 1975. ; __ Les héritiers: les étudiants et la culture. Paris: Minuit,

1964.

COLÓQUIO LUSO-BRASILEIRO SOBRE QUESTÓES CURRICULARES, 4. 2008, Florianópolis. Anais... Florianópolis: UFSC, 2008. 
COSTA, M. et al. Desigualdade na educação: educação e desigualdade no Brasil. Petrópolis: Vozes, 1984.

DUBET, F. O que é uma escola justa? A escola das oportunidades. São Paulo: Cortez, 2008.

EVANGELISTA, O. Algumas questóes em torno da relação políticaeducação. Perspectiva, Florianópolis, ano 8, n. 14, p. 29-57, jan./jun.1990.

Anísio Teixeira e a educação: um roteiro possível de leitura (1930-1950). Perspectiva, Florianópolis, ano 11, n. 20, p. 87-125, ago./ dez.1993.

FIOD, E. G. M. Ensino de 2o grau, hoje: a reafirmação do óbvio. Perspectiva, Florianópolis, ano 1, n.1, p. 85-98, ago./dez.1983.

. Escola pública e educação do trabalhador. Perspectiva, Florianópolis, v. 8, n. 14, jan./jun. 1990.

GIRARDI, C. I. Educação pré-escolar: necessidade e realidade. Perspectiva, Florianópolis, ano1, n. 2, p. 20-25, jan./jun.1984.

HANNAH, J. Educação continuada e outros desafios para um mundo em mudança. Perspectiva, Florianópolis, ano 18, n. 33, p. 115-123, jan./ jun. 2000.

IDEOLOGIA meritocrática e currículo: análise da Revista Perspectiva/ CED/UFSC (1983-2005). In: COLÓQUIO LUSO-BRASILEIRO SOBRE QUESTÕES CURRICULARES, 4. 2008, Florianópolis. Anais... Florianópolis: UFSC, 2008.

KAUFMANN, J.-C. L'invention de soi: une théorie de l'identité. Paris: Armand Colin, 2004.

KOCH, Z.M. Sistema de avanços progressivos: a política educacional dos anos 70/80 em Santa Catarina. Perspectiva, Florianópolis, ano 13, n. 23, p. 27-45, jan./jun. 1995.

KREIMER, R. História del mérito. Local: editora, 2000. Disponível em: <http://geocities.com/filosofialiteratura>. Acesso em: 7 mar. 2007.

PEREIRA, L. A. Crise da universidade, crise da educação ou crise da sociedade brasileira? Perspectiva, Florianópolis, ano 3, n. 7, p. 17-25, jul./ dez. 1986. 
SAUL, A. M. A. A avaliação Educacional. Idéias, São Paulo, n. 22, p. 6168, 1994. Disponível em: <http://www.unifa.aer.mil.br/dep/Avaliacao/ ARTIGOS/>. Acesso em: 23 ago. 2009.

SENA, G. O. Avaliação, assunto de sérias polêmicas no ensino de 1 음 grau. Perspectiva, Florianópolis, ano 1, n. 1, p. 46-49, ago./dez.1983.

SHIROMA, E. O. Educação profissional e profissionalização de educadores. Perspectiva, Florianópolis, ano 18, n. 33, p. 77-91, jan./jun. 2000.

SIQUEIRA, M. L. Aproximando-se da escola: algumas consideraçóes à luz das idéias de Michel Foucault. Perspectiva, Florianópolis, ano 8, n. 15, p.70-90, jul./dez.1990.

VALENÇA, V. L. C. A violência na escola: da palmatória à violência suave. Perspectiva, Florianópolis, ano 5, n. 10, p. 42-48, jan./jun.1988.

O papel da Instituição escolar no fracasso de crianças de classes populares. Perspectiva, Florianópolis, ano3, n. 5, p. 110-120, jul./ dez.1985.

VALLE, I. R.; RUSCHEL, E. A meritocracia na política educacional brasileira (1930-2000). Revista Portuguesa de Educação, Porto, Po, v. 22, n. 1, p. 179-206, 2009. ; . Política educacional brasileira e catarinense (1934-1996): uma inspiração meritocrática. Revista Eletrónica de Investigación y Docência, Brasil; Espanha, n. 3, p. 73-92, jan. 2010. Disponível em: <http://www. ujaen.es/revista/reid/numeros_br.html>. Acesso em: 25 nov. 2010.

VAN ZANTEN, A. Les sciences sociales et l'école. In VAN ZANTEN, A. (Org.). L'école, l'état des savoirs. Paris: La Découverte, 2000, p. 5-14. 


\section{L'idéologie méritocratique} et la réflexion académique: la contribution de la Revue Perspectiva du CED/UFSC (1983-2005)

\section{Résumé}

Dans cette étude nous analysons des articles publiés par la Revue Perspectiva du Centre de Sciences de l'Éducation/ Université Fédérale de Santa Catarina Brésil (1983-2005). Notre intérêt s'est tourné vers l'idéologie méritocratique, en ayant comme référence l'ensemble des termes qui ont rapport à cette conception. Pour cela, nous avons répertorié les Revues dès sa parution en 1983 aux numéros publiés dans les années 2005, rassemblant 47 revues et 425 articles. D'abord, nous analysons les titres ainsi que les résumés des articles, ce qui nous a permis une première sélection. En suite, nous avons fait une lecture systématique des articles sélecionnés (au total 14), ce qui a rendu possible de construire quelques groupes thématiques. Ceux-ci ont été l'objet d'une étude plus minutieuse, ce qui a permis d'établir des relations et des corrélations entre la démocratisation de l'enseignement et la méritocratie, entre la sélection méritocratique dans une école démocratique et la formation des enseignants dans un système d'enseignement méritocratique.

Mots-clés: Méritocratie Scolaire. Démocratisation de l'Enseignement. Revues Scientifiques. Formation des Enseignants.

\section{The ideology of meritocracy and academic analysis: contributions from the journal Perspectiva from CED/UFSC (1983-2005)}

\section{Abstract}

This study analyzes articles in the journal Perspective published by the Center for Educational Sciences at the Federal University of Santa Catarina, Brazil, from 1983 to 2005. It focuses on the ideology of meritocracy, based on terminology related to this concept. To do so, we reviewed all of the editions, since publication began in 1983 until 2005, including 47 issues and 425 articles. We first analyzed the titles and abstracts of the articles, which allowed us to make an initial selection. We then conducted a systematic reading of the 14 selected articles, which allowed us to construct some thematic groups. These were studied in more detail, which made it possible to reflect on the relationship between the democratization of teaching and meritocracy, meritocratic selection in a democratic school and teacher training in a meritocratic system.

Keywords: Educational meritocracy. Democratization of Education. Scientific Journals. Teacher Training. 


\section{Elizete Ruschel}

E-mail: elizeteruschel@yahoo.com.br

\section{Ione Ribeiro Valle}

Departamento de Estudos Especializados da Educação. Centro de Ciências da Educação. Universidade Federal de Santa Catarina, Campus Universitário Trindade.

Telefone: (48) 37219245

E-mail: ionevalle@ced.ufsc.br/ione.valle@pq.cnpq.br.

Recebido em: 14/9/2009

Aprovado em: 23/2/2010 